it may be speculated that they accounted for the repeated episodes of sudden pain and subsequent fever and hyperbilirubinaemia for which no other cause could be found. The pathogenesis of the infarcts is quite unknown.

Our patient died a relatively sudden cardiopulmonary death almost 2 years after HMR was diagnosed. She had proven coronary artery disease but undoubtedly the chronic anaemia contributed to her death and the normoblasts in her peripheral blood had risen shortly before death to $25 \%$ of nucleated cells. We know of no previous patient who survived so long and this case suggests that the prognosis in HMR need not be as uniformly gloomy as previous reports would imply.

\section{Acknowledgments}

The authors wish to thank Dr William F. O'Toole of the Department of Pathology at the Cape Cod Hospital, Hyannis, Massachusetts, who performed the necropsy and kindly supplied tissue for microscopic examination. They also thank Dr Robert Hershberg (Department of Pathology, Massachusetts General Hospital) who examined the microscopic sections. The authors are grateful to Dr Alan C. Aisenberg (Department of Medicine, Massachusetts General Hospital) and to Dr William S. Beck (Department of Medicine, Massachusetts General Hospital), both of whom read the manuscript and made useful comments.

\section{References}

Asher, R. (1946) Histiocytic medullary reticulosis-a case without lymphadenopathy. Lancet, ii, 650.

BoAKe, W.C., CARD, W.H. \& Kimmey, J.F. (1965) Histiocytic medullary reticulosis: concurrence in father and son. Archives of Internal Medicine (Chicago), 116, 245.

Clark, B.S. \& Dawson, P.J. (1969) Histiocytic medullary reticulosis presenting with a leukemic blood picture. American Journal of Medicine, 47, 314.
Chih-Fei, Y., Chung-Hang, T. \& Huai-Teh, H. (1960) Histiocytic medullary reticulosis. Chinese Medical Journal, 80, 466.

De Villiers, D.M. (1969) Histiocytic medullary reticulosis. South African Medical Journal, 43, 756.

Greenberg, E., Cohen, D.M., Pease, G.L. \& Kyle, R.A. (1962) Histiocytic medullary reticulosis. Proceedings of the Staff Meetings of the Mayo Clinic, 37, 271.

Hirsh, J., Ungar, B., King, W.E. \& Lubbe, T.R. (1964) Histiocytic medullary reticulosis: a case report. Australasian Annals of Medicine, 13, 269.

Lutman, G.B. \& Senhauser, D.A. (1966) Histiocytic medullary reticulosis: report of a case with autopsy findings. Southern Medcial Journal, 59, 1345.

LyNCH, E.C. \& Alfrey, C.P. (1965) Histiocytic medullary reticulosis-hemolytic anemia due to erythrophagocytosis by histiocytes. Annals of Internal Medicine, 63, 666.

Marshall, A.H.E. (1956) Histiocytic medullary reticulosis. Journal of Pathology and Bacteriology, 71, 61 .

MEDFORD, M.E. (1965) Histiocytic medullary reticulosis. Archives of Internal Medicine (Chicago), 116, 589.

Natelson, E.A., LyNCh, E.C., Hettig, R.A. \& Altrey, C.P. (1969) Histiocytic medullary reticulosis. Archives of Internal Medicine (Chicago), 122, 223.

RAPPAPORT, H. (1966) Tumors of the Hematopoietic System. p. 49. Armed Forces Institute of Pathology, Washington, D.C.

ScotT, R.B. \& Robb-Smith, A.H.T. (1939) Histiocytic medullary reticulosis. Lancet, ii, 194.

Serck-Hanssen, A. \& Purchit, G.P. (1968) Histiocytic medullary reticulosis-report of 14 cases from Uganda. British Journal of Cancer, 22, 506.

Vaithian Ithan, T., Fishkin, S. \& Gruhn, J.G. (1967) Histiocytic medullary reticulosis. American Journal of Clinical Pathology, 47, 160.

Willcox, D.R.C. (1952) Haemolytic anaemia and reticulosis. British Medical Journal, 1, 1322.

ZAK, F.G. \& RUBIN, F. (1961) Histiocytic medullary reticulosis. American Journal of Medicine, 31, 813.

Zawadski, Z.A., Pena, C.F. \& Fisher, E.R. (1969) Histiocytic nedullary reticulosis-case report with electron microscopic study. Acta Haematologica, 42, 50.

\title{
Idiopathic retroperitoneal fibrosis
}

\author{
L. R. PATHAK \\ M.S., F.R.C.S.
}

\section{R. C. RENJHEN M.S.}

IDIOPATHIC retroperitoneal fibrosis is now a recognized clinical entity, about 200 cases having been reported since Ormond first described it in 1948. While reviewing the literature we discovered that Albaran, a French urologist, first reported a case of ureteral envelopment and obstruction by a fibrous mass in the pelvis in 1905, and he performed ureterolysis for it. Many names have been given to it: periureteral fibrosis, Gerota's fasciitis, perirenal fasciitis, sclerosing retroperitonitis, sclerosing lipogranuloma and non-specific retroperitoneal inflammation, but usually idiopathic retroperitoneal fibrosis or Ormond's syndrome.

This disease is an aggressive, non-malignant, midline fibro-proliferative process which envelops the major retroperitoneal vessels and secondarily 
obstructs the ureters. The diagnosis of retroperitoneal fibrosis is often delayed, usually due to poor clinical understanding of the manifestation of this disease.

\section{Case report}

M. K. L., a 54-year-old male was admitted to Willingdon Hospital on 4 July, 1968, with the complaint of pain in the right lumbar region for the last 20 days. The pain was dull in nature and radiater towards the medial side of the thigh. There was no history of frequency of micturition, dysuria or pyuria. For the last 6 months he had been having pain in the back with a stretching feeling over the back of the right thigh. He was also experiencing malaise and exhaustion after little exertion. He was being treated with steroid and indomethacin for the backache and was also given a course of antiamoebic treatment for his abdominal symptoms.

On admission his blood pressure was $140 / 80$ $\mathrm{mmHg}$ and a bimanually palpable lump was present in the right lumbar region which was not tender. A diagnosis of right-sided hydronephrosis was made.

Urinanalysis showed occasional RBC and WBC with albumin. The specific gravity was 1016 , culture sterile. Blood urea $60 \mathrm{mg} / 100 \mathrm{ml}$, total and differential blood count, serum protein, electrolytes and blood sugar normal.

Straight X-ray of the abdomen and the excretory urogram on 27 June 1968, showed hydronephrosis and hydroureter of the proximal part on the left side with no function on the right side. Retrograde pyelography (Fig. 1) on 8 July 1968, showed hydro-

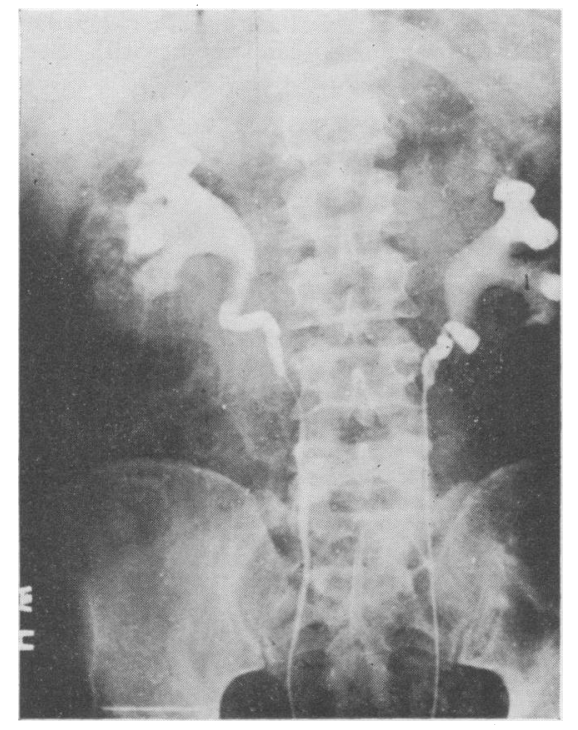

FIG. 1. Retrograde pyelography showing marked hydronephrosis on the right side and moderate on the left side; with medial displacement of both the ureters. nephrosis and hydroureter involving the uppe portions on both sides with narrowing of th ureters, with medial displacement of both the ureters. $\mathrm{He}$ was diagnosed pre-operatively as a case of. retroperitoneal fibrosis involving both ureters?

On 18 July 1968 the left kidney and the ureter were explored through a left lumbar incision retro흘. peritoneally. The upper third of the ureter and the renal pelvis were dilated. The middle part of the ureter was encircled with fibrous tissue which wa\& very hard and cartilagenous, and there was gross. kinking and narrowing. Ureterolysis was done slowly and carefully to avoid damage; after devasculariza $\vec{\imath}$ tion the ureter was placed in the muscular bed of the psoas muscle. The postoperative period was uno eventful and patient was discharged on 31 July 1968 . Postoperative excretory urography on 7 September 1968, showed hydronephrosis on the left side but much less than before and no excretion of the dye on the right side.

\section{Second admission}

He was admitted on 17 September 1968 for operation on the right side. His blood urea was $40 \mathrm{mg}$ $100 \mathrm{ml}$ His right kidney and ureter were explored onf? 23 September, 1968, through a right lumbar incision retroperitonally. The renal pelvis and the proxirate portion of the ureter were dilated and kinked. Thes middle third of the ureter was buried in a fibras tissue sheath even more than the left had been. Theo ureterolysis was done in a similar manner as on the left side. The postoperative period was uneventfu $\overline{\mathrm{p}}$ and the patient was discharged on 7 October $1968 \%$ Steroids were given to him for about 4 months aftep the last operation.

Histopathology of the fibrous tissue from both sides: 'dense fibro-collagenous tissues infiltrated diffusely by chronic inflammatory cells mostly lym phocytes, round cells, plasma cells, and occasionallyp eosinophils with perivascular infiltrates. In some areas of this fibrous connective tissue some fat cells were found and follicle-like collections of lympho cytes were also seen in places. This retroperitonea? connective tissue was found to enclose several blood vessels and nerve tissue. The fibrosis appeared to bein the healing stage (organization) of some kind of self-limited inflammatory process. There was no evidence of any neoplastic process or abscesses'. N

The last excretory pyelogram on 18 December, $N$ 1969 (Fig. 2), showed function on the left side with hydronephrosis less than before and some function ${ }^{\omega}$ on right side. The patient was last examined on 7 November 1970, when he was feeling better and his blood urea was $34 \mathrm{mg} / 100 \mathrm{ml}$.

\section{Discussion}

Retroperitoneal fibrosis usually predominates in 


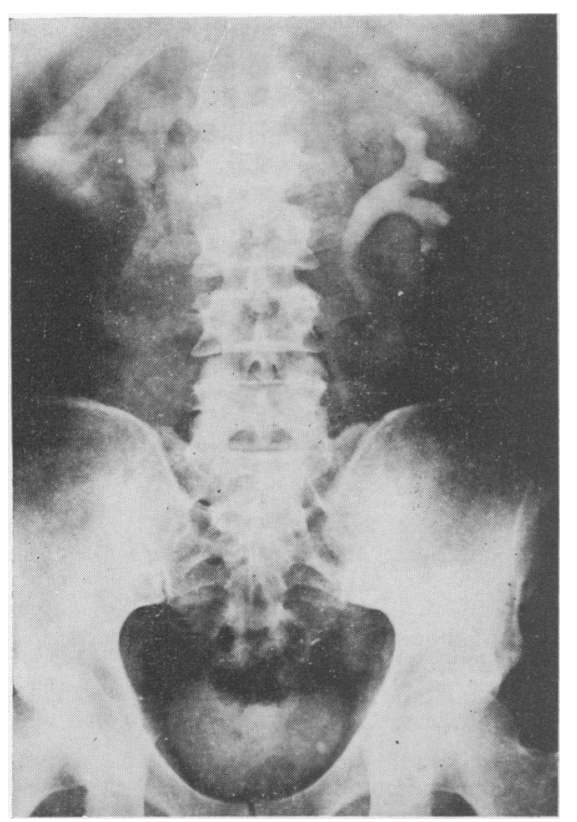

FIG. 2. IVP after second operation showed some function on the right side. Hydro-nephrosis was still present on the left side, but was less than before.

males in a ratio of more than $2: 1$. The great majority of cases are adults, only two being under 10 years, the oldest was 73 years.

Many explanations have been offered for the etiology and pathogenesis of this disease. The role of infection in the lower extremities or lower urinary tract has been emphasized by Hache, Utz \& Woolner (1962), Vest \& Barelare (1953) and Mulvaney (1958). Specific infection of the retroperitoneum such as syphilis, brucellosis and tuberculosis have been considered as possible causes. Raper (1955) and Hoffman \& Tripple (1961) have proposed that the initial lesion may be an allergic vasculitis and that the fibrosis which eventually forms is simply a tissue reaction.

Graham et al. (1965), Mulvaney (1958) and Utz et al. (1965) suggested that ingestion of sansert or ergot preparations has caused this condition in patients who have been taking this medicine for migraine; stopping this therapy has resulted in some cure.

Hoffman \& Tripple (1961) suggested that this disease may be a response to some undetermined allergen, either bacterial, autogenous tissue or of extraneous origin manifesting itself in the retroperitoneal reticulo-endothelial tissue. Organizing haematoma due to spontaneous or traumatic haemorrhage has been suggested by Oppenheimer \& Goldman (1962) recently but all the clinical evidence and the fact that the fibrosis differs in pattern from that of organizing haematoma are against it.
Mulvaney (1958) states that the similarity to Dupuytren's contracture and Peyronie's disease has been noted and vascular disease was thought to be a common denominator. However, there are apparently no cases of the later two entities associated with retroperitoneal fibrosis. Ormond (1948) and Hache et al. (1962) believe that retroperitoneal fibrosis should be classed with the collagen diseases, all of which are systemic diseases with local manifestations and not with Peyronie's disease or Dupuytren's contracture which are initially local diseases. Samella (1961) suggested that abdominal inflammatory lesions such as diverticulitis of the colon, regional ileitis, ulcerative colitis, appendicitis or pelvic surgery may produce secondary retroperitoneal fibrosis and obstruct the ureter. Charnock, Riddell \& Lombardo (1961) have emphasized the similarity on a morphologic basis between retroperitoneal fibrosis and WeberChristian disease (sclerosing lipogranuloma), but have no theories to explain it. Kendall \& Lahey (1961) have described a case of Hodgkin's disease associated with ureteral obstruction. Trevor (1958) believes that tumor of some sort is responsible and can produce fibrosis but this has not been proved by repeated sectioning of the tissue. Partington (1961) also belives it to be a systemic disease characterized by a widespread fibrosis often in the neck and mediastinum in addition to the retroperitoneal space.

In spite of all these speculations, the etiology remains unknown The pathology of retroperitoneal fibrosis is non-specific. Grossly, there is an ill-defined, non-encapsulated fibrous mass in the retroperitoneal space 2-6 cm thick It extends upwards to the upper border of the renal pelvis and occasionally down into the pelvis covering and enveloping the retroperitoneal structures (glands, vessels, nerves, muscle and ureters) but rarely invading them. As the ureters are most easily compressible most of these patients go to the urologists. Microsection of the tissue shows fat in variable amount and fibrous tissue described as collagenous, cartilagenous, or hyaline, sometimes in whorls with different degrees of infiltration by wandering and mononuclear cells, eosinophils and neutrophils. In some fibrous tissue a collection of lymphocytes was described. Abscesses were found rarely. In general, the longer the duration of the process, the less fat and fewer inflammatory cells were seen. In only a very few instances was the tissue cultured, showing no growth in some and growth of Proteus and $E$. coli in others.

The onset of the disease is insidious and the presenting symptoms seem to be unrelated to urinary tract disease, being usually low back or abdominal pain, weight loss, non-specific gastrointestinal symptoms, generalized malaise and azotemia, as were noted in our case. In later stages the patient comes with anuria or uraemia. 
This condition has characteristic findings on excretory urography and ascending urography as demonstrated in our case. Graham et al. (1965) have used lymphangiography in the diagnosis of this condition but Halverstadt (1968) states that it may not always be conclusive in this disease and an abnormal lymphangiogram is not always an absolute diagnostic criterion for idiopathic retroperitoneal fibrosis.

The definitive treatment favoured is ureterolysis in the early stages but for a patient coming with uraemia or anuria this is combined with nephrosotomy or ureterostomy. The ureters can be approached retroperitoneally on either side but this has the disadvantage of not preventing re-investment of the ureter by the fibrotic process. To overcome this certain special procedures such as closing the channel or filling it with fat, or transplanting the ureter away from its former course, or wrapping the ureter with fat, or embedding it in a muscular bed are advisable.

The ureters can be approached transperitoneally and this was advocated by Ormond (1948) and Raper (1955) as the better approach, as both the ureters can be inspected and treated and moreover the chances of re-investment with fibrosis are rare as the posterior peritoneum is stitched beneath the freed ureters. This procedure has however, the drawback that ureteroplasty or nephrostomy, if desirable, is made more difficult.

Shaheen \& Johnston (1959) have recorded a case in which the recurrence of ureteral obstruction with symptoms after bilateral ureterolysis was successfully treated with cortisone. Radiotherapy was suggested by Oppenheimer, Narins \& Simon (1952) and Bradfield (1953) for the treatment of this condition but its success has not been proved. Harrow \& Solan (1962) think that the radiosensitivity of the fibrous mass may be due to its marked vascularity. With all these empirical therapies there is no record of the plaque remaining unchanged or receding although the patient might show clinical improvement.

\section{References}

Albaran (1905) Quoted by Hache et al. (1962).
BRADFIELD, E.O. (1953) Bilateral ureteral obstruction due tôِ compression by chronic inflammation. Journal of Urology,, 69, 769.

ChaRnOCK, D.A., Riddell, H.I. \& Lombardo, L.J. Jr.e (1961) Retroperitoneal fibrosis producing ureteral obstruc- tion. Journal of Urology, 85, 251.

Graham, J.R., Suby, H.I., KerR, W.S., Jr., \& Fraley, E. (1965) Retroperitoneal fibrosis-a missing link in the chain.? Journal of Urology, 93, 144.

HACHE, L., UTZ, D.L. \& WoolNer, L.B. (1962) Idiopathic fibrosis retroperitonitis. Surgery, Gynaecology and $O b-\vec{\Phi}$ stetrics, 115, 737.

Halverstad, D.B. (1968) Problem in the use of urographc and lymphangiography in the diagnosis of the idiopathiy retroperitoneal fibrosis. Journal of Urology, 99, 423.

HARROW, B.B. \& SolAN, J.A. (1962) Idiopathic retroperi- $\overrightarrow{-}$ toneal fibrosis. Journal of the American Medical Associa- $\vec{\omega}$ tion, 182, 38.

HofFMAN, W.H. \& TriPPle, O.T. (1961) Retroperitoneak fibrosis-etiological consideration. Journal of Urology, 86, 222.

Kendall, A.R. \& LAHEY, W.H. (1961) Sclerosing Hodgkin. disease vs. idiopathic retroperitoneal fibrosis. Journal of Neurology, 86, 217.

MulvaneY, W.P. (1958) Periureteritis obliterans-a retroperitoneal disease. Journal of Urology, 79, 410.

ORMOND, J.K. (1948) Bilateral ureteral obstruction due to윽 envelopment and compression by inflammatory retroperi- toneal process. Journal of Urology, 59, 1072.

OPPenheimer, G.D. \& Goldman, H. (1962) Periureteral $\frac{\rho}{\overparen{Q}}$ fibrosis, an unusual complication of renal biopsy. Journgl of Urology, 88, 611.

OPPENheiner, S.D., NARINS, L. \& Simon, M. (1952) Radig- $-\overrightarrow{0}$ therapy in treatment of non-specific inflammatory strictu of ureter. Journal of Urology, 67, 476.

Partington, P.F. (1961) Diffuse idiopathic fibrosis. American Journal of Surgery, 101, 239.

RAPER, F.P. (1955) Idiopathic retroperitoneal fibrosis involving the ureter. Journal of Urology, 82, 436.

SAmella, W. (1961) Ureteral obstruction due to compression $\stackrel{\circ}{\mathbb{D}}$ by an idiopathic retroperitoneal inflammatory process. Journal of Urology, 85, 828.

ShAHEen, D.J. \& Johnston, A. (1959) Bilateral ureteral obstruction due to an inflammatory retroperitoneal process. Journal of Urology, 82, 51.

TREVOR, R.W. (1958) Reticulum cell sarcoma producing retroperitoneal periureteric fibrosis. New England Journal of Medicine, 258, 268.

Utz, D.C., Rook, E.D., SPITTEK, J.A. \& BARTholemew, L.G. (1965) Methgysergide and retroperitoneal fibrosis. Journal of the American Medical Association, 191, 983.

Vest, S.A. \& Barelare, B. (1953) Periuretritis plastica. Journal of Urology.

\section{Amoebic pericarditis}

\author{
B. C. BANSAL \\ M.D.
}

\section{S. GuPTA \\ M.B., B.S.}

\section{Medical College Hospital, Rohtak, India}

IN 1860, Rouis from Algeria published the necropsy findings of a patient with 'tropical abscess' of the liver which had extended into the pericardium. Germillon (1899) is credited with the first clinical diagnosis of amoebic pericarditis. Lamont \& Pooler $\stackrel{0}{\mathscr{C}}$ (1958) reported that the frequency of amoebic peri- $\stackrel{\oplus}{?}$ carditis is about $2 \cdot 8 \%$. Takara \& Bond (1958) reported the frequency of amoebic pericarditis to be 